\title{
Transparency, asymmetric information and cooperation
}

\author{
Gianna Lotito $^{1} \cdot$ Matteo Migheli $^{1,2}$ (1) $\cdot$ Guido Ortona ${ }^{3}$
}

Accepted: 17 September 2020 / Published online: 16 October 2020

(c) The Author(s) 2020

\begin{abstract}
We inquire experimentally whether asymmetric information in competitive settings and competition per se influence individual social behaviour. Participants perform a task and are remunerated according to two schemes, a non-competitive and a competitive one, then they play a standard public goods game. In the first scheme participants earn a flat remuneration, in the other they are ranked according to their performance and remunerated accordingly. Information about ranking and income before the game is played varies across three different treatments. We find that competition per se does not affect the amount of contribution. The time spent to choose how much to contribute is negatively correlated with the decision of cooperating fully. The main result is that full information about the relative performance in the competitive environment enhances the cooperation, while partial information reduces it.
\end{abstract}

Keywords Incomplete contracts · Asymmetric information · Competition · Cooperation $\cdot$ Public goods $\cdot$ Experiments

JEL Classification C91 $\cdot$ D80 $\cdot$ H41

\section{Introduction}

Asymmetric information is a central topic of the economics literature (Hillier 1997) and is strictly related to the theory of incomplete contracts (Grossman and Hart 1986). Full information and contractual completeness is indeed one of the

Electronic supplementary material The online version of this article (https://doi.org/10.1007/s 1065 7-020-09669-z) contains supplementary material, which is available to authorized users.

Matteo Migheli

matteo.migheli@unito.it

1 Department of Economics and Statistics "Cognetti de Martiis", Università di Torino, Lungo Dora Siena 100, 10153 Turin, Italy

2 Turin Centre on Emerging Economies, Piazza Arbarello, 8, 10123 Turin, Italy

3 DiGSPES, Università del Piemonte Orientale, via Cavour, 15100 Alessandria, Italy 
fundamental hypotheses on which the theory of perfect competition rests: indeed full and perfect information is assumed during all the performance of a contract, since when it is signed until all the obligations are completed. Competitive markets with incomplete contracts are therefore imperfect, and, indeed, economic theory considers asymmetric information within the category of the failures of perfectly competitive markets. Such an incompleteness stands for the absence of some pieces of information about what would happen if some circumstances, which are not explicitly mentioned in the contract, occurred. In this context, Spier (1992) shows that asymmetric information on the quality of the parties of a contract may also lead to contractual incompleteness, which, however, signalling may solve. Indeed, in presence of performance incentives, agents are induced to signal their ability through effort. Such an issue is of particular importance also in the labour market, where negotiations between employers and employees are affected by asymmetric information and therefore lead to incomplete contracts, although reciprocity may arise in presence of contract incompleteness and may serve to mitigate it and its effects (Fehr et al. 1997; Gächter and Fehr 2002). Milgrom and Roberts (1992) cite the absence of explicit performance incentives as a form of contract incompleteness that may lead to labour market inefficiencies, i.e. to the inability of principals to identify their agents' types, because of the lack of incentives. Gächter and Fehr (2002) claim also that reciprocity between agents and principals is likely to stem from contractual completeness: employees may return the employer's generosity by increasing their effort.

Rousseau and Greller (1994) highlight that, even when contracts are complete, each party must trust the counterpart to respect the contract and act consequently. Asymmetric information plays a role here: if the occurrence of some circumstance is invisible (or opaque) to one of the contractual parties, then it will be unable to understand whether the contract is honoured or not. In this sense, a complete contract, whose performance is affected by informative opaqueness might result in inefficient outcomes ( $\mathrm{Li}$ and $\mathrm{He} 2013$ ), as an incomplete contract would. In other words, in presence of private information, the subject who acts under the veil of ignorance may suspect that her counterpart is not applying the contractual clauses fairly, as she cannot check it.

The possible effect that transparency, meant as disclosure of information about the implementation of contractual clauses in a competitive setting, may have on social interactions is the basis of this paper. In the light of the extant experimental literature, we first hypothesise that competition may result in less cooperation, but transparency (about some aspects of interaction) may mitigate such a negative effect. Indeed, as mentioned above, we are studying a main feature of competitive markets, and therefore, in order to disentangle the effect of transparent information and that of competition, we need to inquire the existence of a competition effect. Our hypothesis of a possible causal link between competition-as one characteristic aspect of market interaction-and the propensity to cooperate is based on two considerations. On the one hand, we believe that the hypothesis of selfishness as the sole determinant of human behaviour is a reductive way of extending the behaviour in competitive markets to all aspects of economic interaction (for a similar point of view see for instance Fehr and Schmidt 2001). On the other, we share the view that economic institutions like markets not only have the function to allocate goods and 
services, but also influence the evolution of individual preferences, i.e., the whole set of 'values, tastes and personalities' that constitute the 'cultural trait' of an individual, so that social preferences and tastes depend on the institutional environment (Bowles 1998, 2011). In particular, we concentrate on one aspect of market interaction, competition, and its effect on cooperative behaviour in the form of the propensity to contribute in a public goods game. The issue of the relation between markets and values has been discussed broadly in the literature, and prosocial behaviour has been analysed empirically in many cross-cultural studies. ${ }^{1}$ However, to our knowledge few contributions have used experiments in a controlled environment to study the relation between market interaction, information and pro-social behaviour. ${ }^{2}$ Our study wants to fill this gap in the experimental literature, by studying how exposure to a competitive environment has any effect on the individual disposition to contribute voluntarily to the provision of a public good.

The second aspect relates to the role of transparency. In addition to what already highlighted at the beginning of the section, Arnott et al. (1994) show the important role of information in fostering economic efficiency, where the latter increases as the former does. A way to ensure that relevant information reaches all the market agents is to enforce rules that promote transparency, i.e. the disclosure of potentially relevant information. An example of such a policy is the regulation of advanced financial markets (Vishwanath and Kaufmann 2001), where transparency decreases trading costs and increases liquidity of exchanged securities (Kim et al. 2014; Boone and White 2015). The link between transparency and efficiency has also been inquired experimentally, for example in terms of welfare, where it has been seen that as information disclosure increases, so does the level of social welfare (Rietz et al. 2013). However, the link between transparency and behaviour in a competitive setting has not yet been explored.

The existing literature shows that experiments are a valuable way to inquire the relationships existing between norms and economic outcomes (Galbiati and Vertova 2014; Holt and Sullivan 2017; Deffains et al. 2019). Therefore, this paper proposes an experiment that aims at inquiring into the following effects of competition and transparency on cooperation, as it emerges in a public goods game. First, we ask whether competition has any effect on the willingness to give any positive amount to the voluntary provision of a public good. Second, whether the knowledge of the results of the competition in terms of ranking and remuneration (which is the way transparency is implemented in this paper) affects one's contribution to the public good. As will be discussed later in detail, we disclose this information to the subjects, but at different stages of the experiment. The effect of such difference has not yet been studied, to our knowledge. However, Espín et al. (2017) find that when the future is perceived as predictable people tend to cooperate more; this may suggest that cooperation is stronger when more information is disclosed. The potential

\footnotetext{
1 See below for references.

2 We will review these studies below.
} 
relevance of this paper in the field of law and economics follows from the fact that the experiment inquires how regulation (which establishes and enforces competition and transparency) affects cooperation. ${ }^{3}$

In the following section, the related literature is reviewed; the experimental design, hypotheses and procedure are described in Sect. 3, and we introduce the experimental methodology in Sect. 4; in Sects. 5 and 6 the descriptive and econometric results are given, and Sect. 7 concludes.

\section{Related literature}

The idea that economic institutions may have an influence on individual agents' preferences is well grounded in the literature (Bowles 1998, 2011; Carpenter 2005). In this view, preferences have broadly to be intended as 'attributes' of individuals, which contribute to account for their actions, and so their definition includes values or what has been defined by Harsanyi (1982) 'moral preferences'.

Market is one of the many economic institutions. An effect that markets and other economic institutions have on preferences is on the evolution of norms through the influence they have on the structure of social interaction. ${ }^{4}$ What is relevant for our discussion is that subset of norms which Bowles (1998) calls 'nice traits', that is, that kind of behaviours that in social interaction 'confer benefits to others' (page 92) like, for instance, contributing in a public goods game or cooperating in a prisoner's dilemma game.

The literature offers two opposite views concerning how markets influence the way in which individuals behave towards each other in social interactions (for a classic discussion see Hirschman 1982). According to one theory, the doux-commerce thesis of Montesquieu, Adam Smith, Thomas Paine and Condorcet, a complex system of interactions through market relies - in order to develop and flourish - on moral and social values, such as trust and propensity to cooperate (Falk and Szech 2013). ${ }^{5}$ In this view, 'commerce' is seen as a powerful moralizing agent that produces a positive externality, that is, compatible psychological attitudes and moral dispositions. The second theory-the self-destruction thesis which dates back to Marx and finds in Hirsch (1976) a more recent influential discussion-is that the market undermines and erodes those same moral values that are its foundations and are necessary for its functioning. The discussion of the mechanisms through which the market as an economic institution has the effect of 'crowding out virtues' (Bowles 2011) is very relevant for this work.

First of all, the impersonality and anonymity together with the transitory nature of market interactions reduce the opportunity to sanction violation of norms and, therefore, to reward 'nice traits'; besides, they increase the cost of acquiring information

\footnotetext{
3 The law and economics approach, indeed, consists in analyzing how legal rules affect economic variables (Marciano and Ramello 2019).

${ }^{4}$ For a complete discussion of the several effects, that market and other economic institutions have on preferences see Bowles (1998).

5 A similar view is found in Sugden (2018).
} 
about others' behaviour and thus decrease the incentive of acquiring a reputation. ${ }^{6}$ In addition, the erosion of socially beneficial behaviour may occur when a choice situation is framed as a competitive market, with many anonymous agents. According to this view, the focus on the competitive aspect of interaction and on the pursuit of self-interest as an ethically permissible rewarding strategy, together with the anonymity of trade, displaces other-regarding behaviour and ethical values. ${ }^{7}$

The issue of how economic institutions-like markets-affect social preferences has been discussed widely both in theoretical and empirical studies. ${ }^{8}$ As mentioned above, few contributions have used controlled experiments in order to study the relation between market interaction and moral values, and in particular, the effect of competition on the propensity to cooperate. Falk and Szech (2013) present experimental evidence on how interaction in a bilateral and multilateral double auction trading markets affects moral values, in particular the willingness to accept negative consequences for a third party with respect to individual decision making. According to their hypothesis, the interaction in markets would lead to an erosion of moral standards due to three essential characteristics of market: sharing and thus diluting the responsibility of negative consequences; observing others violating moral norms thus making self-interest ethically permissible; and framing choices by focusing attention on aspects like trade and competition, instead of the moral aspects of choice. The results of the experiment confirm what was expected. The authors find that in both market settings the willingness to kill a mouse in exchange for money (negative consequence for a third party) is significantly higher than in an individual decision setting, and in the multilateral market the exchange is accepted for an even lower amount of money.

Brandts et al. (2009) study the effects of competitive rivalry on the disposition towards others in a social dilemma game without complete contracts. They find that rivalry increases neither efficiency nor the income of those on the short side of the exchange relation; in addition, it has a negative effect on the subjective well-being of those on the long side, and a positive one on those on the short side, therefore generating inequalities. More importantly, in analysing the consequences that rivalry may have on well-being, they conclude that interacting under rivalry impacts negatively on people's behavioural disposition towards others, mostly towards those encountered in the interaction, who they can meet again in the future. The "subsequent willingness to help" decreases and may lead to the "obstruction of future cooperation" and "a deterioration of the social relations between interaction partners". Significantly, they note that these effects cannot be explained only by differences in earnings due to interaction, but "are strongly related to experienced emotions" (page 1166).

Carpenter (2005) conducts an experiment to measure the effects of economic institutions on people's social preferences, with the intent to assess whether and how

\footnotetext{
${ }^{6}$ For other important mechanisms like the erosion of segmentation and group selection see Bowles (1998) and references therein.

7 The framing or 'construal' effect of markets and related experimental evidence are discussed in Bowles (1998, 2011).

8 A list of references on the empirical studies concerning the effects of economic institutions and markets on values is in Bowles (1998, 2011), Falk and Szech (2013). Relevant cross-cultural studies on the topic are Heinrich et al. (2001, 2010), Hermann et al. (2008), Roth et al (1991).
} 
some features traditionally associated with markets, in particular anonymity and competition, affect individuals' preferences for other people's well-being. Results show that reducing anonymity makes people "more social", as it reduces people's ability to engage in opportunistic acts. More importantly, market competition "erodes social preferences", not only because it encourages opportunistic behaviour, thus "creating a less friendly atmosphere", but also because the market institution itself - through a sort of framing effect—“decreases the other-regardingness" of the participants (page 3). A negative effect of competition on the propensity to cooperate has also been found by Canegallo et al. (2008), who study subjects' contribution to a public good in three different economic environments characterized by different degrees of competition.

Similar experimental findings are discussed in Hoffman et al. (1994), who examine the effect of the framing of interactions on ultimatum bargaining outcomes, and find that when they are framed as market interactions the distribution of the surplus is significantly affected (sellers offer much less of the surplus to buyers). Markets appear to stimulate more egoistic behaviour, with a deterioration of social preferences. Schotter et al. (1996) show that the introduction of competition reduces offers in the ultimatum game, suggesting that competition makes participants more selfish.

Transparency may play a role in this framework. On the one hand, as the introduction points out, it is an essential ingredient of market efficiency and, as such, is generally promoted by economic theory. On the other hand, human actions and interactions are based on trust and on the counterparts' behaviour (Camerer 2003). A consequence of this is that the more information agents have about their counterparts, the more accurate their responses are. Information is important both for knowing better the environment in which one is operating in order to make accurate decisions, and for trusting (or not) the other agents. As Rietz et al. (2013) show experimentally transparency-implemented in terms of information that each player has about the others' actions-affects social welfare through enhancing individual trust. In particular, the more information a player has about the others' decisions, the more she trusts the others. Correctly placed trust also increases the efficiency of markets. Transparency not only concerns information about the others' actions, but also about the processes of decision.

A few experiments in economics have inquired the relationship between transparency, individual choices and consequent outcomes. Greiner et al. (2011) conduct an experiment on wage differentials, showing that when the determination of wages is transparently disclosed to the subjects, their performance responds to the economic incentive represented by wage differentials, while, when their mechanism is not disclosed to the subjects, effort and performances do not depend on such differentials, even if their existence is known to the subjects. In other words, transparency about the mechanism of wage formation affects individuals' choices. Işgın and Sopher (2015) conduct an experiment, which shows that information transparency enhances efficiency (i.e. workers' effort for a given wage) and welfare in the labour market. In their experiment transparency is implemented as follows: firms offer jobs and wages commensurate to the productivity level of each job. When submitting information about job vacancies, transparent firms disclose both the wage and the productivity level associated to the jobs; opaque firms announce wages but keep information 
about productivity private. The experimental results show that workers spend more effort in the assigned tasks in the full information treatment than in the other. The authors interpret such a result as a consequence of perceived fairness: in case workers perceive that they are treated fairly, they are more willing to spend effort. Fiala and Suetens (2017) conduct a meta-analysis on a series of experiments on voluntary contributions and decisions in oligopolistic settings. They focus on the role of transparency, finding that when public goods games are analysed, disclosing information about the earnings of the components of each group of players decreases the average contribution of the (other) members of the group, while displaying information about individual choices made by other players in the group tends to lead to an increase in contributions. ${ }^{9}$

In sum, part of the experimental results reviewed above suggests that the more the experimental situation is framed as a competitive market (with complete contracts) with many anonymous players, the less cooperative and less other-regarding the behaviour observed will be. Besides, other results show the relevance of transparency in enhancing trust, promoting efficiency and, partly, inducing cooperative behaviour. Our experimental design aims at offering an experimental contribution to these two branches of literature.

As outlined in the introduction, the main research question of the paper concerns the possible effect that transparency, which we interpret as disclosure of information about the implementation of contractual clauses in a competitive setting, may have on social interaction.

First, we ask whether competition in the performance of a task has any effect on the willingness to contribute any positive amount to the voluntary provision of a public good. The question whether markets erode moral values is one of the most controversial issue in the literature, and we have reviewed part of the debate above. In the paper we concentrate on one feature of market interaction-competition-and its effect on one aspect of others' regarding behaviour-the propensity to cooperate as voluntary contribution to the provision of a public good. Our first hypothesis is that exposure to competition may reduce people's propensity to contribute. The possible mechanisms with which this may occur emerge from the above discussion of the contributions to the literature - framing, anonymity, impersonality, transitory nature of market interaction.

Second, we inquire whether different levels of information concerning the results of the task performed in a competitive environment affects contributions to the public good. These results concern the subject's remuneration from the task and her ranking in its performance. The knowledge concerning these two aspects of the competitive performance represents the way in which we implement in the experiment transparency in contract implementation. Our second hypothesis is that transparency in the implementation of contracts enhances cooperation. As discussed above, several contributions in the literature show the relevance of disclosure of relevant information in promoting decision accuracy and efficiency-for instance as a consequence of perceived fairness; enhancing trust and therefore social welfare; and promoting collusive and cooperative behaviour.

\footnotetext{
${ }^{9}$ Consistently with this result, in oligopoly experiments information about payoffs significantly reduces the degree of collusion, while information on the individual choices of other group members increases it.
} 
As will emerge from the discussion of the experiment treatments, we decided to disclose the information concerning remuneration and ranking in the competitive performance at different stages of the experiment. Relying on some experimental results, like for instance Espín et al. (2017) quoted above, our hypothesis is that cooperation will be stronger (the contribution to the public good higher) the higher the level of the information disclosed.

\section{Experimental design and procedure}

We designed an experiment with two steps and four treatments, and we implemented a repeated public goods game (PGG) with re-matching, so that each subject always played each round against subjects who were all different from those of the other rounds. A total of 160 subjects participated in the experiment, 40 for each treatment. All of them were students of the School of Economics of the University of Torino (Italy). We recruited them by advertising for the experiment on the webpage of the School, and they enrolled following an online procedure. No show up fee was given. Each experimental session involved 20 participants. Full anonymity was granted during and after the experiment. The PGG, which will be described in detail below, allows capturing the subject's propensity to cooperate, when facing the choice between free-riding and contributing to the provision of a public good. Of course, this last decision entails the risk of being the sole contributor, while the other members of the group decide to free-ride. This situation would end in a net loss for the only contributor, whereas the case in which all the members of the group contribute their entire endowments maximises the social payoff.

\subsection{Effort task}

The experiment was made of two parts. In the first the participants were asked to perform an administrative-type task consisting in recopying in a form on the screen of their PC the enrolment numbers, the names and the scores of fictitious students; the names and the other data were created by choosing at random a string of letters and figures. A quadruplet made of enrolment number, surname, name and mark entered correctly in the form made a completed unit of the task. In the case of mistakes, the program alerted the participant and did not allow him or her to continue before the mistake had been corrected.

The first difference between the treatments concerns the remuneration of this part of the experiment. We implemented two schemes, a non-competitive and a competitive one; the first provides the baseline for assessing the effect of competition. In the non-competitive scheme the subjects received a remuneration of $8.5 €$ if they copied correctly 40 quadruplets in $30 \mathrm{~min}$ and $4 €$ if they did not finish the task. The program announced the end of this part of the experiment either when the 40th 
quadruplets had been entered, or after $30 \mathrm{~min} .{ }^{10}$ Instead, in the competitive scheme the number of lines to be copied was not limited, and at the end of the task, i.e. after $30 \mathrm{~min}$, the subjects were ranked according to their performance, and the payments were differentiated. The players falling in the best group of 5 obtained $15 €$, those in the second best group $10 €$, those in the third $6 €$ and those in the last $3 €$. The payment in the baseline treatment (i.e. 8.5€) corresponds to the expected payment under the competitive treatment. The players copied on average 80.08 quadruplets under the competitive scheme, i.e. twice the goal assigned in the non-competitive framework. This proves that the requirement under the non-competitive treatment was easy to accomplish and arguably did not entail competition among the subjects. Before starting the session, the experimenters informed the subjects about the rules. In particular the subjects in the competitive environment knew that they would be divided in four groups according to their performance and that the payments were to be scaled across the groups, with the highest for the best performing group. In contrast, the information about the exact amounts paid to each group and about the actual ranking was provided in different ways across three different treatments, as will be described in detail in the following section.

\subsection{Public goods game}

After performing the described task, the subjects played five rounds of a classical PGG in groups of four anonymous individuals. In order to maximise the number of observations, we re-matched the players after each round, following two rules. The first was random matching (see Andreoni 1988; Botelho et al. 2009), which means that at each round the players were matched with three others who were not members of the same group in the previous or subsequent rounds. ${ }^{11}$ In other words, each player faced three new opponents in each round. The second rule, relevant for competitive treatments, further constrained this re-matching procedure to form the groups so as to always include one player from each of the quartiles in which the players were ranked after the initial task. This procedure was envisaged to avoid any possible effect due to the average amount gained in the first part of the experiment. For instance, contributions may increase with initial income. If three subjects with low initial income and a subject with high initial income compose a group, the latter will possibly contribute more than the former ones in the first round. At the end of the round, when the high-income individual looks at the sum of all the contributions, she could get disappointed by the fact that the other three members contributed less than she did, and this could affect her subsequent behaviour (see Cherry et al. 2005; Buckley and Croson 2006). The composition of the groups described above excludes this effect. Of course, also the opposite may be true: people with higher initial income may contribute less. In order to avoid any effect of this type, the groups were composed in the way described. However, given the capacity of the lab (20 seats), this procedure allowed for a maximum of five rounds of the PGG.

\footnotetext{
${ }_{10}$ It never occurred that a subject did not complete the task in the 30 min allocated.

11 Of course, all players were informed about this.
} 
The players who performed the task in the competitive environment played the PGG under three different treatments, representing three different levels of transparency. Indeed, the difference concerned the information about their position in the ranking and the income they received in the first part. In the first treatment neither the position in the ranking nor the remuneration from the first part was disclosed before the PGG; this information was given them only at the very end of the experiment, i.e. after playing the PGG. The second treatment entailed the disclosure of the information about the income obtained in the first part, but not of the ranking, before playing the PGG; the subjects knew their position in the ranking after the PGG. In the third treatment the complete information about placement and income from the first part was disclosed before the PGG. To sum up, the participants played the PGG either (1) knowing neither their ranking nor their income, (2) knowing only the income, but not the ranking, and (3) knowing both. The difference between these three treatments aims at disentangling the effects of competition. The comparison of the blind treatment with the baseline treatment (where there was no competition) isolates the effect of working under competitive pressure, separate from the effect of income or pride (or frustration) arising from knowing one's position in the rank. The comparison between the blind treatment and that with partial information aims at identifying the effect of the initial endowment on the contributions to the PGG. Finally, the treatment with full information isolates the effect of knowing the position in the ranking due to the comparison between this treatment and the others. Informing somebody about a good result in a game may contribute to stimulate her happiness, inducing the "winners" of this first part of the game to contribute more (Drouvelis and Grosskopf 2016 and Layous et al. 2017). A summary of the characteristics of the design is given in the following Table 1.

At the beginning of each of the five rounds of the PGG the participants received a fresh endowment of 60 experimental coins, each worth $0.01 €$. The subjects then had to decide whether to keep them for themselves or to allocate all or part of them to a common fund, knowing that the total amount contributed would be doubled and then redistributed in equal shares among the members of the group at the end of each round. The coins kept by the subject remained as her earning. ${ }^{12}$ The subjects also knew that they would have always been matched with strangers at the beginning of each round. Between one round and the following the subjects viewed the total amount contributed and their gain in that round. At the end of the PGG the total payoff (the sum of what was earned in each of the five rounds of the PGG plus the gain of the first part of the experiment) was displayed. As we know, in this kind of PGG the unique Nash equilibrium predicts always to contribute nothing to the common fund (complete free-riding), while the Pareto-efficient solution (full cooperation) predicts allocation to the fund of the whole endowment.

\footnotetext{
${ }^{12}$ Letting $\mathrm{E}$ be the initial endowment, $\mathrm{S}$ the sum of the contributions of the four subjects, and $\mathrm{c}_{\mathrm{i}}$ the experimental coins allocated by individual $i$ to the fund, in each round $i$ 's payoff $\mathrm{P}$ was then $P_{i}=E-c_{i}+(2 / 4) S=E-c_{i}+1 / 2 S$.
} 


\subsection{Experimental procedure: practical details}

At the beginning of each session, the subjects were asked to sit at 20 different isolated computer terminals, so that no communication was possible. The instructions appeared sequentially on each participant's computer screen and would proceed to the following page only when all the participants had clicked on the 'Continue' button on the screen, while they were read aloud by an experimenter at the same pace. ${ }^{13}$ When the instructions on the first part of the experiment were over, the time for the completion of the task started running. The list with the data to be copied as well as the rows with the empty fields appeared sequentially on each participant's screen. In the treatments with competition the countdown in seconds of the time remaining was displayed on the top right hand-side of the screen. When the time was over the information about the ranking and/or income was given according to the treatment. Then, the second part of the experiment started. The PGG was illustrated to the subjects, both on the screen and by the same experimenter. It was made clear that: the game would be played in groups of 4 participants unknown to each other and that the composition of the group would change at each round, with no re-encounters; that all the initial sum would be kept as earnings in case no coin was allocated to the common fund; that in each round the earnings in case all participants allocated all the sum to the fund would be twice the initial endowment; and that no amount could be transferred from one round to the following one.

After the description a written summary of the instructions was distributed to the participants and this part of the experiment started. In each repetition the subjects faced a screen with an empty box where they had to enter the amount of coins they wanted to allocate to the common fund. After each subject had taken the decision or the time allocated had passed, ${ }^{14}$ a new screen for a new round appeared. In every repetition, each subject could see summarized in a table the total amount of the common fund, her earnings for that round, the amount of coins kept by her, and the division of the common fund and her total profit up to that round. At the end of the 5 rounds, the total earnings from the experiment (first and second part) appeared on the screen. Once the experiment was over, the subjects were asked to fill in a questionnaire, which appeared on the screen, and then they were asked to leave the room and come back individually to fill in their receipts and be paid in order to preserve full anonymity among participants.

\section{Experimental strategy and empirical methodology}

Two figures were of interest: the contribution to the PGG and the share of extreme behaviours, that is full free riding (i.e. contributing 0 to the PGG) and full cooperation (i.e. contributing the entire endowment of 60 experimental coins). At each

\footnotetext{
13 The experimenter was the same for all sessions.

14 Fixing a maximum time for the decision is common practice, for the experiment not to be blocked. In such a case, the programme set the contribution equal to 0 , and the game proceeded to the next round. The individual received nothing for that round (the endowment was destroyed). This event never occurred.
} 
Table 1 Summary of the characteristics of each treatment

$$
\text { Competition }
$$

Information on payment first part
Information on position in the rank

\begin{tabular}{llll}
\hline Baseline treatement $(\mathrm{BL})$ & No & No & No \\
Full ignorance treatment (IG) & Yes & No & No \\
Partial information treatment (PI) & Yes & Yes & No \\
Full information treatment (FI) & Yes & Yes & Yes \\
\hline
\end{tabular}

round, the contribution to the PGG is bounded between 0 and 60 . We therefore treat this variable as a truncated continuous variable, and analyse the effects of the treatments on it with panel tobit regressions, following Moffatt (2016) ${ }^{15}$ A model with random mixed effects could have been suitable too, however, the panel tobit model was chosen for two reasons: (1) the choice of how much to contribute is exogenously limited; the subjects may want to contribute more than their endowment, or they may desire to subtract some from the common fund, but they are not allowed to. Consequently, their decisions are "truncated" by the rules of the game; (2) a large mass of probability could accumulate on the two extreme values (0 and 60). In such a case, OLS estimation may produce biased and inconsistent results (Moffatt 2016), while tobit procedures are suitable to correct these overloads, which render the underlying distribution of the dependent variable non-Gaussian. We specify three different models to check whether the effects of the treatments are robust to different specifications. In particular, in the first we include: the dummies for the different treatments, the time spent by the subject to decide how much to contribute, the time spent in looking at the results of the previous round, a variable that captures the round, and two one-period-lagged dummies for the extreme behaviours (free riding and full contribution). In the second specification we replace these extreme choices with the value of the fund (i.e. the sum of all the four contributions) and the average contributions of the other three members of the group. ${ }^{16}$ Both these last controls are presented lagged by one and two rounds to capture their persistence on the individual choices. ${ }^{17}$ With respect to the first specification the third model removes the extreme choices (and the time-to-see-results variable) and introduces a variable that captures the difference between the player's contribution in round $t$ and the average contribution to the fund, without much difference in results. This variable captures whether the subject is more or less cooperative than the mean of the other members of the group.

\footnotetext{
${ }_{15}$ In particular, Moffatt (2016, pp. 193-197) applies tobit regression to data from a public goods experiment.

${ }^{16}$ This is calculated as follows: $c_{-i, j, t}=\frac{1}{3}\left(F_{j, t}-c_{i, j, t}\right)$ where $c_{-i, j, t}$ is the average contribution to the PGG of the subjects other than subject " $\mathrm{i}$ " who belong to group $\mathrm{j}$ at time $\mathrm{t} ; F_{j, t}$ is the amount of the fund of group $\mathrm{j}$ at time $\mathrm{t}$, and $c_{i, j, t}$ is the contribution of subject $\mathrm{i}$ who belongs to group $\mathrm{j}$ at time $\mathrm{t}$.

17 The dummies for extreme behaviours and the lagged value $c_{-i, j, t}$ are not introduced in the same model, to minimise multicollinearity.
} 
The extreme choices are instead modelled separately: we constructed dummy variables for free-riding or contributing the full endowment at each round. In this case we analyse the data using probit regressions.

Whereas we designed the experiment in order to render the observations independent of each other at every round, gains and the others' contributions in a round may affect a subject's choice in the subsequent ones. Therefore, we ran panel regressions and, for each individual, we controlled for both the lagged value of her contribution to the PGG and of the average contributions of the other three members of the group. In this way we capture the "learning" effect, i.e. the effect that playing in a group of co-operators (non-co-operators) in round $t-1$ (and $t-2$ in a second estimated model) may have on one's decisions in round t. We capture the well-known decreasing trend of contributions to the PGG (see for instance Camerer 2003; Ledyard 1995; Chaudhuri 2011) controlling for the round. Moreover, we control for the time spent in choosing the contribution and for the time spent in looking at the results in the previous round. Under the assumption that these times proxy for the subject's degree of instinctiveness used in the decision process (Rubinstein 2007, 2013; Piovesan and Wengström 2009 and Lotito et al. 2013), this will therefore clean the results from the "instinctiveness" component. We also control for the participant's gender ( 1 if male, 0 if female), and-in one of the three estimated models - for a couple of dummies that capture whether the subject had fully cooperated (i.e. contributed 60 experimental coins) or free-rode in the previous round. This helps to clean the results from the possibility that someone had a pre-conceived strategy of pure contribution or pure free-riding. We control also for the voluntary social activities conducted by the subjects (as detected from the questionnaire), in order to capture the possible effect of pro-social attitudes. In the econometric analysis presented below we do not control for the income gained in the first part of the experiment, as we have introduced it in several estimations, but it had never shown any statistically significant effect. ${ }^{18}$

The described empirical analysis allows to control for path dependency, but, unfortunately, does not for individual fixed effects. Indeed, as each participant is subjected to only one treatment, running panel regressions with fixed effects would not allow to identify the effect of the different treatments. A possible-though partial-solution to this problem is to consider the average contribution of each participant over the five rounds, collapsing the five time-variant observations into a single observation. Regressions based on this strategy are presented in the Appendix.

We performed also an analysis of the response times to understand the degree of instinctiveness behind the subjects' decisions (Rubinstein 2007, 2013), in order to assess whether the presence of competition and the information about one's position in the competitive ranking render the decision more or less instinctive.

\footnotetext{
18 Income is not statistically significant even in the treatment where only the wage gained in the first part of the experiment is disclosed before the PGG.
} 


\section{Results: descriptive and graphical analysis}

The performances in the three treatments with competition in the first part of the experiment are not statistically different (see Table 2), which suggests that the subjects involved in these treatments had statistically the same ability, and therefore the differences on the other outcomes cannot be attributed to heterogeneity in abilities. Male subjects recopied correctly more quadruplets that their female peers, which might reflect the fact that competition has different effects on the two genders, with males more responsive than females to competition (Niederle and Vesterlund 2007; Migheli 2015). This gender effect might affect the results as follows: if males are more competitive and they work harder than females, then we will end with more males than females receiving a high income from performing the task. Indeed, there is an average difference of $0.89 €$ in the sub-sample of subjects who recopied the quadruplets in a competitive setting. This difference is statistically significant (at $1 \%$ level) but is small both in value and in relative terms (it amounts to $10.5 \%$ of the average income from the first part). Finally, we note that the time employed by the subjects to choose how much to contribute to the PGG is decreasing with the level of information disclosed before the PGG. We will return on this result later.

Table 3 presents the descriptive statistics for the variables used in the subsequent analyses. We may observe a certain variability between the contributions in the different treatments. Most noticeably, full information about both the ranking and the income from the first part enhances considerably the contributions to the PGG with respect to all other cases.

Figure 1 presents the average contributions per treatment and by round for the full game. Here too we can observe some interesting outcomes. First, while for the treatment with full information we observe almost no decline in the average contribution to the PGG, in the other treatments we observe a decline. Subjects who played with no or partial information reduce their average contributions more than the subjects in the baseline treatment. These outcomes suggest that competition per se has a negative effect on cooperation. In addition, the lines in the graph suggest that disclosing information plays a key role in sustaining cooperation. Indeed, all the subjects start from average levels of contribution that are similar and statistically not different from each other. However, as the subjects interact, cooperation decreases, as it happens in the baseline treatment (consistently with what usually found in the literature). In other words, competition seems to have a negative effect on the conservation of cooperation, rather than on cooperation itself. Instead, transparency about remuneration sustains cooperation, and generates increasing and statistically significant differences between average contributions under full information and under other conditions. In addition, statistical tests on these differences reveal that in the full-information setting the average contributions are not statistically different over the five rounds.

The comparison between the contribution in the first round and those in the other rounds is informative about how long cooperation lasts in time. Indeed, in the first round players have no information about the average level of cooperation of their game mates; this is no longer true from the second round on, when 
Table 2 Recopied quadruplets and treatments

\begin{tabular}{ll}
\hline Male & 4.669 \\
Competition with partial information (wage only) & $(1.560)^{* * *}$ \\
& 0.643 \\
Competition with full information & $(1.187)$ \\
& -1.680 \\
Constant & $(1.877)$ \\
& 77.657 \\
Observations & $(1.578)^{* * *}$ \\
R-squared & 160 \\
Root-MSE & 0.017 \\
\hline
\end{tabular}

OLS estimates (s.e. in brackets)

players choose after observing the average contribution of the other players who are in the same group. In other words, the contribution in the first round represents the unconditional level of cooperation of the player, while in the subsequent rounds we observe individual cooperation conditioned to what happened in the past. For this reason, to analyse how long cooperation lasts, it is common in the literature (Andreoni 1988; Cadsby and Maynes 1998; Milinski et al. 2002; Croson et al. 2005) to compare the average contributions in the rounds from the second to the last with the average contribution in the first round. In particular, we aim at capturing the first round in which the average contributed sum is statistically different from that in round 1 . The first round in which the average contribution is statistically different from the average contribution in round 1 captures the round from which we can assess, with statistical support, that contributions have started to decrease. Figure 1, indeed, shows that the average contributions decrease monotonically in all the treatments, except that with full information. Using this strategy, we observe that in all the treatments, but that with full information, the decrease between the first and the fifth round is always statistically significant at $5 \%$ or even at $1 \%$. In the baseline treatment the decrease of the contribution with respect to the first round is statistically significant from the fourth round (38.95 coins in the first against 29.62 in the fourth $-p$ value $=0.034-$ and 29.30 in the fifth $-p$-value $\left.{ }^{19}=0.029\right)$. In the competitive treatment with no information about the ranking or about the income, the decrease with respect to the first round is statistically significant from the third round (39.57 coins in the first, against 31.02 in the third $-\mathrm{p}$-value $=0.041-27.05$ in the fourth $-\mathrm{p}$-value $=0.001-$ and 19.30 in the fifth-p-value $<0.001)$. In the setting with partial information, the decrease with respect to the first round also becomes statistically significant since the third round (from 35.35 coins in the first to 26.95 coins in the third $-\mathrm{p}$-value $=0.057-$ to 19.32 in the fourth $-\mathrm{p}$-value $=0.0001-$ to 20.20 in the fifth-p-value $=0.002$ ). All this is important. It suggests that competition disrupts cooperation when there

\footnotetext{
${ }^{19}$ Here and below the $p$ value refers to the statistical significance of the difference between the average contribution in round $\mathrm{t}$ (for $\mathrm{t}=3,4,5$ ) and the average contribution in round 1.
} 
Table 3 Descriptive statistics: average values and their standard deviations (in brackets)
Average contribution (experimental coins)

Full sample

Baseline treatment

Competition with full ignorance

Competition with partial information (wage only)

Competition with full information

Performance in the task (average number of quadruplets correctly recopied by the subjects)

Full sample

Baseline treatment

Competition with full ignorance

Competition with partial information (wage only)

Competition with full information

Individual characteristics

Subjects who volunteer (\%)

$\operatorname{Males}(\%)$

Average choice times (in seconds)

Full sample

Baseline treatment

Competition with full ignorance

Competition with partial information (wage only)

Competition with full information

Percentage of free-riding episodes ${ }^{\mathrm{a}}$

Percentage of full co-operation episodes ${ }^{\mathrm{a}}$

${ }^{\mathrm{a}}$ Calculated on the total number of observations (number of subjects $\times$ rounds) 


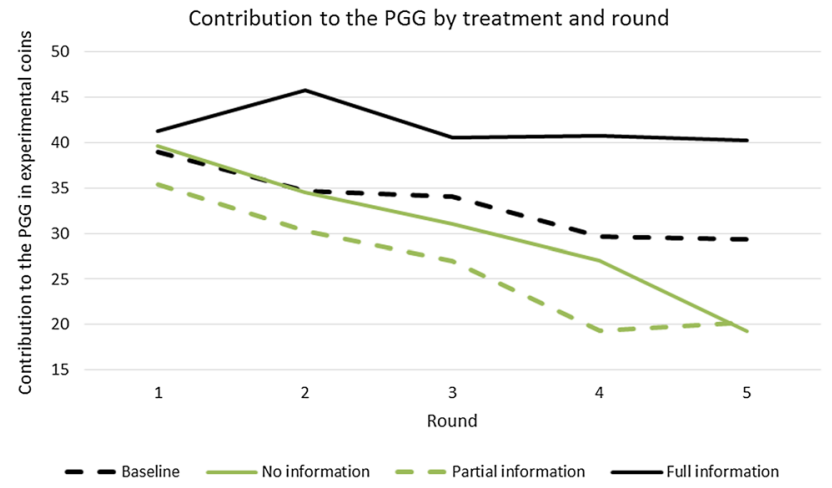

Fig. 1 Contribution to the PGG by treatment and round

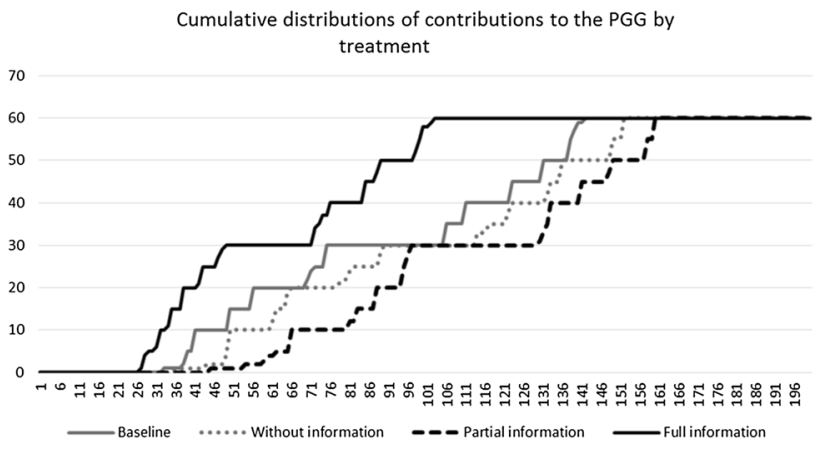

Fig. 2 Cumulative distributions of contributions to the PGG by treatment

is full or partial ignorance, while it enhances both the level of the contribution and the maintenance of a high level over time (rounds) when there is full knowledge. Also, the data show that partial ignorance (i.e. when only the information on the income earned is disclosed) hinders cooperation more than full ignorance. The relevance of knowledge was unexpected; data do not provide an indication about its cause. We will suggest a few possible explanations in the last section.

Figure 2 presents the cumulative distributions of the contributions in the four treatments. We can observe that in the baseline and in the treatments with no or only partial information the density of free-riders and of subjects with low contributions is much larger than in the treatment with full information. In addition, the share of contributions equal to the whole endowment (60 experimental coins) is much higher in this last treatment than in all the others. This result is also unexpected and relevant; we will return to it.

Table 4 completes the picture reporting the percentage of times in which a subject made an extreme choice (either free-riding or contributing the entire initial endowment). The statistical significance of the differences is tested through a Mann-Whitney test. These percentages are calculated on the total number of choices made (this 
Table 4 Pair-wise comparisons of extreme behaviours and of average contributions by treatment (standard errors in brackets)

\begin{tabular}{|c|c|c|c|c|c|c|}
\hline & \multirow[t]{2}{*}{$\%$ of free-riding episodes } & \multicolumn{4}{|c|}{ Significance with respect to treatment ${ }^{1}$} & \multirow[t]{2}{*}{ Observations } \\
\hline \multirow[b]{2}{*}{ Baseline } & & $\mathrm{BL}$ & IG & $\mathrm{PI}$ & $\mathrm{FI}$ & \\
\hline & $\begin{array}{c}16.00 \\
(36.75)\end{array}$ & & - & * & - & 200 \\
\hline Competition with ignorance & $\begin{array}{c}17.00 \\
(36.66)\end{array}$ & - & & * & * & 200 \\
\hline Competition with partial information (wage only) & $\begin{array}{c}22.00 \\
(41.53)\end{array}$ & * & * & & *** & 200 \\
\hline \multirow[t]{2}{*}{ Competition with full information } & $\begin{array}{r}12.00 \\
(32.58) \\
\end{array}$ & - & * & $\star \star \star \star$ & & 200 \\
\hline & $\begin{array}{c}\% \text { of full co-operation } \\
\text { episodes }\end{array}$ & $\mathrm{BL}$ & IG & $\mathrm{PI}$ & $\mathrm{FI}$ & \\
\hline Baseline & $\begin{array}{l}29.50 \\
(3.23)\end{array}$ & & - & $* \star$ & $* \star *$ & 200 \\
\hline Competition with ignorance & $\begin{array}{l}24.50 \\
(3.05)\end{array}$ & - & & - & $\star \star \star \star$ & 200 \\
\hline Competition with partial information (wage only) & $\begin{array}{l}20.50 \\
(2.86)\end{array}$ & ** & - & & $\star \star * \star$ & 200 \\
\hline \multirow[t]{2}{*}{ Competition with full information } & $\begin{array}{l}49.00 \\
(3.54) \\
\end{array}$ & $\star \star \star *$ & *** & $\star \star \star \star$ & & 200 \\
\hline & Average contribution & \multicolumn{4}{|c|}{ Significance with respect to treatment ${ }^{1}$} & Observations \\
\hline \multirow[b]{2}{*}{ Baseline } & & $\mathrm{BL}$ & IG & $\mathrm{PI}$ & $\mathrm{FI}$ & \\
\hline & $\begin{array}{c}33.31 \\
(1.596)\end{array}$ & & - & *** & *** & 200 \\
\hline Competition with ignorance & $\begin{array}{c}30.31 \\
(1.610)\end{array}$ & - & & - & 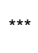 & 200 \\
\hline Competition with partial information (wage only) & $\begin{array}{c}26.41 \\
(1.632)\end{array}$ & *** & - & & $* * \star$ & 200 \\
\hline Competition with full information & $\begin{array}{r}41.70 \\
(1.579) \\
\end{array}$ & $* \star *$ & *** & 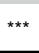 & & 200 \\
\hline
\end{tabular}

${ }^{1}$ Mann-Whitney tests

Legenda: $\mathrm{BL}=$ baseline; $\mathrm{IG}=$ with ignorance; $\mathrm{PI}=$ with partial information (wage only); $\mathrm{FI}=$ with full information

Significance levels: ${ }^{\star \star \star} 1 \%$; ${ }^{\star \star} 5 \% ;{ }^{*} 10 \%$; - not significant at conventional levels

renders the number of observations equal to 800: 160 subjects times 5 rounds). The subjects free-rode much less and contributed the full amount much more frequently in the treatment with full information than in the other treatments. In particular, the effect is much stronger for the cases in which the subjects contributed the full amount. Indeed, the share of free-riding decisions is similar in the baseline treatment and in the full-information one, with no significant difference, while the difference is very strong in the case of full cooperation. Apparently, the effect of knowing one's own position in the ranking is more effective in enhancing cooperation than in discouraging free-riding.

The bottom of the Table shows pairwise comparison for average contributions to the public good, by treatment. Given the presence of multiple choices, the standard deviations may be corrected using the Bonferroni or the Scheffe methods; we have chosen this last, as it is one of the most general available. The table reports the levels of statistical significance based on it. The picture is very similar to what emerges from the central panel of the table: in the full-information treatment the average contribution is much higher than in the other treatments, and the differences are always statistically highly significant. The lowest average contribution (26.41 experimental coins) corresponds to the treatment with partial information: this figure is statistically different from those of the baseline and the full-information treatments. The average contribution in the treatment with ignorance is not statistically different from that in the baseline treatment. Information has a role to play: when full information about both the remuneration of the work and the subject's relative position in 
the rank is disclosed, the average contribution is maximised. When information only about the remuneration of the first part of the experiment is disclosed, the average contribution is minimised. This non-monotonic path followed by the average contributions suggests that the effect of information on cooperation depends on which piece of information is released.

In sum, the results of the experiment show that transparency has no effect on the contributions to the PGG in the first round, i.e. no treatment disrupts cooperation at the beginning. However, transparency supports cooperation over the rounds of the game, while in the other treatment conditions, cooperation declines over time, as usually observed in repeated PGGs. While such a result does not allow for concluding that market competition may hinder cooperation, as hypothesised at the beginning of the paper, we can nevertheless observe that transparency preserves cooperation, even in competitive environments.

\section{Results: econometric analysis}

Table 5 reports the coefficients of panel tobit regressions for three different specifications. ${ }^{20}$ The results confirm what has already been suggested by the previous analysis. The baseline treatment is taken as reference; this implies that the coefficients for the three treatments introduced in the regressions are to be interpreted as effects relative to the baseline. The contributions under full information are always significantly larger than those in the baseline, and people contributed significantly less in the partial-information treatment than in the baseline. Moreover, a simple t-test highlights that the coefficients for the full-information treatment are statistically different from the coefficient for the partial-information treatment. This also confirms the previous results. People playing the PGG under the no-information treatment contribute less than people playing the baseline, but the difference is not statistically significant.

The figures in the table also suggest other interesting results. First, in spite of the matching procedure that always generates groups of strangers (i.e. of people who had never played in the same group in any of the previous rounds), the contributions are strongly path-dependent. The coefficients for the lagged values of the contribution (i.e. the sum contributed by individual $i$ in the previous round) and the coefficients for the lagged values of the others' average contribution are statistically very significant. In particular, the value of the contribution at times $t-2$ (L2) and $t-1$ (L1) is linked to the individual contribution at time t positively, while the average amount of the others' contribution has the opposite (i.e. negative) effect. Moreover, the magnitude of the first and second lag coefficients is almost the same, suggesting that the subject discounts the past at a very low rate.

The inclusion of these variables in the regression decreases the coefficients for the partial and the full-information dummies and the associated levels of significance.

\footnotetext{
${ }^{20}$ Contributions were also analysed through panel regressions clustering the standard errors at session level. The statistical significance was never worse than that reported in the table.
} 
Table 5 Panel Tobit analysis of the individual contributions (measured in experimental coins) to the public good (standard errors in brackets)

\begin{tabular}{|c|c|c|c|}
\hline Variables & $\begin{array}{l}\text { (1) } \\
\text { Contribution }\end{array}$ & $\begin{array}{l}\text { (2) } \\
\text { Contribution }\end{array}$ & $\begin{array}{l}\text { (3) } \\
\text { Contribution }\end{array}$ \\
\hline No information & $\begin{array}{l}-5.534 \\
(5.599)\end{array}$ & $\begin{array}{l}-6.648 \\
(4.460)\end{array}$ & $\begin{array}{l}-6.409 \\
(7.687)\end{array}$ \\
\hline Partial information (wage only) & $\begin{array}{l}-11.12^{* *} \\
(5.633)\end{array}$ & $\begin{array}{l}-7.689 * \\
(4.632)\end{array}$ & $\begin{array}{l}-14.58^{*} \\
(7.698)\end{array}$ \\
\hline Full information & $\begin{array}{l}16.08 * * * \\
(5.901)\end{array}$ & $\begin{array}{l}8.852 * \\
(4.608)\end{array}$ & $\begin{array}{l}21.85 * * * \\
(7.967)\end{array}$ \\
\hline Round & $\begin{array}{l}-3.320 * * * \\
(1.262)\end{array}$ & $\begin{array}{l}-0.958 \\
(1.974)\end{array}$ & $\begin{array}{l}-5.824 * * * \\
(1.040)\end{array}$ \\
\hline Mean of the others' contributions (L1) & & $\begin{array}{l}-1.706^{* * *} \\
(0.262)\end{array}$ & \\
\hline Contribution (L1) & & $\begin{array}{l}0.605 * * * \\
(0.0816)\end{array}$ & \\
\hline Mean of the others' contributions (L2) & & $\begin{array}{l}-1.657^{* * * *} \\
(0.261)\end{array}$ & \\
\hline Contribution (L2) & & $\begin{array}{l}0.535^{* * *} \\
(0.0828)\end{array}$ & \\
\hline Time to choose & $\begin{array}{l}0.199 * * * \\
(0.0640)\end{array}$ & $\begin{array}{l}0.152 * * \\
(0.0638)\end{array}$ & $\begin{array}{l}0.200 * * * \\
(0.066)\end{array}$ \\
\hline Time to see results (L1) & $\begin{array}{l}-0.186^{*} \\
(0.110)\end{array}$ & $\begin{array}{l}-0.329^{* * *} \\
(0.123)\end{array}$ & \\
\hline Full cooperation (L1) & $\begin{array}{l}21.95 * * * \\
(4.833)\end{array}$ & & \\
\hline Free riding (L1) & $\begin{array}{l}-13.94 * * \\
(6.456)\end{array}$ & & \\
\hline Male & & & $\begin{array}{l}-5.739 \\
(5.477)\end{array}$ \\
\hline Difference from the average contribution (L1) & & & $\begin{array}{l}0.044 \\
(0.080)\end{array}$ \\
\hline Constant & $\begin{array}{l}37.29 * * * \\
(9.524)\end{array}$ & $\begin{array}{l}8.182 \\
(14.17)\end{array}$ & $\begin{array}{l}63.76^{* * * *} \\
(7.407)\end{array}$ \\
\hline Pseudo R-squared & 0.208 & 0.409 & 0.202 \\
\hline Wald Chi squared & 94.44 & 208.32 & 60.45 \\
\hline Observations & 640 & 480 & 640 \\
\hline Number of subjects & 160 & 160 & 160 \\
\hline
\end{tabular}

Significance levels: $* * * p<0.01, * * p<0.05, * p<0.1$

Arguably, this is a reflex of the persistence over time of the effect of the past experience on the present decision. This suggests that, though the observations in our sample are independent of each other because of the way in which the groups are formed at each round, the individuals anyway internalise the behaviour of the others 
in the previous rounds, and they discount these behaviours at a very low rate (the coefficients are very close to each other over time). Last but not least, the dummy that captures whether the distance from one's contribution and the average contribution at $\mathrm{t}-1$ is positive has a positive coefficient. This suggests that people who tend to be more cooperative in a round remain more cooperative than the average in the subsequent rounds. Gender does not appear to be significantly related to the level of contributions.

Additionally, it can be noted that the amount of time people take to decide how much to contribute is positively and significantly related to the level of the contribution, while the longer they take to see the results from the previous round, the less they contribute. It is noteworthy that specifications 1 and 2 produce effects whose size is very close (specification 2 ) or close (specification 1) to the effect sizes reported in Table 4. Therefore, we consider these two specifications to be the best of the table, and we rely particularly on them, rather than on specification 3 .

Table 6 presents the results of the panel probit estimates for the extreme behaviours. These are defined as perfect free-riding (i.e. contributing 0 experimental coins in a round) and as complete cooperation (i.e. contributing 60 experimental coins, the whole endowment, in a round). The figures in the table confirm what the other analyses have already highlighted. The treatments have no effect on the probability of full free-riding: this behaviour is distributed more or less homogeneously across treatments, although when full information is provided the share of free riding occurrences (i.e. null contributions) in the total number of decisions is slightly lower than in the other cases (but this difference is not statistically significant). Only the average contribution of the other players in round $t-1$ seems to slightly decrease the probability of free-riding in round $t$, but this result is not robust to different specifications (compare columns 1 and 2 of Table 6). The treatment variables are, in contrast, effective in promoting cooperation: in the setting with full information, the probability of contributing all the 60 experimental coins in a round is between 73 and 83 percent higher than in the baseline treatment. This is an impressive figure; we will discuss it in the following section. There is also no significant difference between the baseline and the other two treatments that do not entail full information. Also, the individual contribution in round $\mathrm{t}-1$ increases the probability of contributing the full endowment in round $t$, while the opposite happens for the average contribution of the others. This is in line with the results presented in Table 5. Subjects display a path-dependent behaviour, in the sense that at each round they behave consistently with their past decisions, but apparently try to benefit from the others' high contributions. This appears as a contradiction; but at the end of each round, the subjects see the total value of the fund, while they do not see the others' average contribution nor the others' individual contributions. Since we do not know whether they mentally calculate the others' average contribution, we might suggest that they respond more to the total value of the fund than to the average contribution of the others. From a quantitative perspective, this distinction is not relevant, but from a psychological point of view, it is. There may be two possible interpretations. First, there is some degree of constancy in the subject's behaviour, so that people who start contributing large stakes continue doing so. Second, the individual really 
Table 6 Analysis of extreme contributions. Panel probit estimates (s.e. in brackets)

\begin{tabular}{|c|c|c|c|c|}
\hline Variables & $\begin{array}{l}(1) \\
\text { Free rider }\end{array}$ & $\begin{array}{l}(2) \\
\text { Free rider }\end{array}$ & $\begin{array}{l}(3) \\
\text { Cooperator }\end{array}$ & $\begin{array}{l}\text { (4) } \\
\text { Cooperator }\end{array}$ \\
\hline Male & $\begin{array}{l}0.687 * * \\
(0.295)\end{array}$ & $\begin{array}{l}0.742 * * \\
(0.336)\end{array}$ & $\begin{array}{c}0.118 \\
(0.225)\end{array}$ & $\begin{array}{c}0.121 \\
(0.247)\end{array}$ \\
\hline With no information & $\begin{array}{r}-0.0837 \\
(0.407)\end{array}$ & $\begin{array}{r}-0.0215 \\
(0.460)\end{array}$ & $\begin{array}{r}-0.152 \\
(0.323)\end{array}$ & $\begin{array}{r}-0.194 \\
(0.352)\end{array}$ \\
\hline With partial information (only about wage) & $\begin{array}{c}0.189 \\
(0.392)\end{array}$ & $\begin{array}{c}0.356 \\
(0.452)\end{array}$ & $\begin{array}{l}-0.178 \\
(0.323)\end{array}$ & $\begin{array}{l}-0.248 \\
(0.354)\end{array}$ \\
\hline With full information & $\begin{array}{r}-0.358 \\
(0.416)\end{array}$ & $\begin{array}{r}-0.415 \\
(0.471)\end{array}$ & $\begin{array}{l}0.730 * * \\
(0.329)\end{array}$ & $\begin{array}{l}0.827 * * \\
(0.363)\end{array}$ \\
\hline Round & & $\begin{array}{c}0.213 * * \\
(0.0976)\end{array}$ & & $\begin{array}{r}-0.171 * * \\
(0.0795)\end{array}$ \\
\hline Contribution (L1) & $\begin{array}{r}-0.00780 * \\
(0.00437)\end{array}$ & $\begin{array}{r}-0.00295 \\
(0.00518)\end{array}$ & $\begin{array}{c}0.0243 * * * \\
(0.00468)\end{array}$ & $\begin{array}{c}0.0214 * * * \\
(0.00514)\end{array}$ \\
\hline Average others' contribution (L1) & $\begin{array}{c}0.0162 \\
(0.0144)\end{array}$ & $\begin{array}{c}0.00471 \\
(0.0163)\end{array}$ & $\begin{array}{c}-0.0669 * * * \\
(0.0152)\end{array}$ & $\begin{array}{c}-0.0597 * * * \\
(0.0163)\end{array}$ \\
\hline Time to look at the results of the previous & $\begin{array}{c}0.0170 * * \\
(0.00793)\end{array}$ & $\begin{array}{c}0.00910 \\
(0.00901)\end{array}$ & $\begin{array}{r}-0.0142 * * \\
(0.00630)\end{array}$ & $\begin{array}{r}-0.0101 \\
(0.00682)\end{array}$ \\
\hline Time to make the choice & $\begin{array}{r}-0.00493 \\
(0.00443)\end{array}$ & $\begin{array}{r}-0.00468 \\
(0.00464)\end{array}$ & $\begin{array}{c}0.0184 * * * \\
(0.00431)\end{array}$ & $\begin{array}{l}0.0190 * * * \\
(0.00459)\end{array}$ \\
\hline Income from the initial task & & $\begin{array}{c}0.0142 \\
(0.0406)\end{array}$ & & $\begin{array}{c}0.00481 \\
(0.0312)\end{array}$ \\
\hline Volunteer $($ yes $=1)$ & $\begin{array}{r}-0.581 \\
(0.435)\end{array}$ & & $\begin{array}{c}0.291 \\
(0.307)\end{array}$ & \\
\hline Constant & $\begin{array}{c}-2.498 * * * \\
(0.813)\end{array}$ & $\begin{array}{c}-3.320 * * * \\
(0.951)\end{array}$ & $\begin{array}{r}-0.701 \\
(0.631)\end{array}$ & $\begin{array}{r}-0.304 \\
(0.720)\end{array}$ \\
\hline Pseudo R-squared & 0.181 & 0.187 & 0.239 & 0.336 \\
\hline Log-likelihood ratio test & 50.57 & 57.92 & 19.71 & 23.88 \\
\hline Wald Chi squared & 24.91 & 24.97 & 77.42 & 71.87 \\
\hline Observations & 640 & 640 & 640 & 640 \\
\hline Number of subjects & 160 & 160 & 160 & 160 \\
\hline
\end{tabular}

Standard errors in parentheses

$* * * p<0.01, * * p<0.05, * p<0.1$

responds to the total value of the fund by increasing one's own level of cooperation, but she does not disentangle her own from the others' contributions and her behaviour is unconsciously driven by her past decisions.

Interestingly, the time spent by a subject in looking at the results increases the probability of free-riding (column 1), and decreases that of contributing the whole endowment (column 3). However, these results are not robust to different 
specifications. The time spent to choose how much to contribute is not relevant in the case of free-riding but is positively correlated with the decision to cooperate fully. $^{21}$

All the results reported in the previous tables include lagged variables, excluding the results of the first round of the experiment. As a robustness check, the same specifications as those presented in Table 5 are used for regressions that include also the results of the first round of the experiment; the estimates are reported in Table 7 in Appendix. The figures confirm the findings reported in the other tables, which, therefore, are not biased by the exclusion of the results of the first round.

As mentioned at the end of Sect. 4, Table 8 in Appendix shows some additional robustness checks. The results are in line with the panel regressions, thus confirming them.

\section{Conclusions}

The results of the paper suggest that complete contracts not followed by transparent information about their implementation may be detrimental for individuals' prosocial behaviour. Our experiment aimed at assessing the effect of competition and transparency on cooperation. The first hypothesis was that exposure to competition reduces people's propensity to cooperate, arguably due to the enhancement of a selfish mood stimulated by the competition. The second hypothesis was that transparency in the implementation of contracts enhances cooperation. We found mixed support for the first hypothesis, while the results support the second one. In absence of information about the results of the competition, the propensity to cooperate was unaffected (Table 5, line 1). Note that this result is not conclusive: it is possible that the competition was too feeble to actually induce a selfish mood, or that "they came to play" effect (see Carpenter et al. 2006) prevailed. All what we can infer is that the effect of competition, if existent, is too small to appear in the setting of our experiment. Instead, we found that competition has a significant effect if the information that accompanies it is varied. Partial information reduces the propensity to cooperate (Table 5, line 2), but full information (or transparency) strongly enhances it (Table 5, line 3). In the light of the extant literature on transparency, our results provide some evidence about its effects on cooperation and suggest that disclosing information not only enhances the efficiency of markets, but also promotes pro-social behaviours. Consequently, legislators should keep spending effort in promoting and implementing transparency. We may also provide some additional interpretations of the results obtained. The first has to do with the notion of overall security. ${ }^{22}$ A person feels

\footnotetext{
21 Lotito et al. $(2013,2015)$ obtained, in a setting devoid of rivalry, that the decision time inversely correlated with the degree of cooperation. The double evidence suggests that cooperation is spontaneous in non-competitive settings, while it requests some thinking when the possibility of strategic behavior by other subjects may be more relevant, thus displacing the instinctive behavior. However, data are (still) too limited to establish this conclusion.

22 Garrone and Ortona (2013) found that overall security, as self-assessed following the economics of happiness approach, strongly correlates with several relational and economic items. The definition
} 
more secure the more she knows all the relevant features of the environment that surrounds her; and a secure person, arguably, is more prone to help. In our setting the full knowledge of one's own position in the game produces a feeling of security, while a partial knowledge adds an element of uncertainty to the environment, and hence reduces security; while a total absence of information de-emphasizes the security concern. However, the study of security as such is in its infancy (see Garrone and Ortona 2013 for a discussion of the meaning of the notion); hence, what has been stated above is highly speculative. The second possible interpretation relates to fairness: people, who are told that their remuneration is fair compared to that of their competitors, as it reflects their relative performance, are more willing to contribute to the common good. This is so because if the payment for a work is perceived as fair, negative sentiments such as envy and resentment are minimised. This could be an extension of the idea of conditional cooperation (see Fischbacher et al. 2001). Indeed, people evaluate fairness not only looking at the results of some behaviour, but also at the intentions behind that behaviour (Falk and Fischbacher 2006). In this sense, the subjects who know both their position in the ranking and their payment may feel that their remunerations are intentionally fair, and therefore they show a high level of cooperation (conditional on how they have been previously treated). Note that the two explanations are not mutually exclusive, and that both require further evidence to be assessed.

Funding Open access funding provided by Università degli Studi di Torino within the CRUI-CARE Agreement.

Open Access This article is licensed under a Creative Commons Attribution 4.0 International License, which permits use, sharing, adaptation, distribution and reproduction in any medium or format, as long as you give appropriate credit to the original author(s) and the source, provide a link to the Creative Commons licence, and indicate if changes were made. The images or other third party material in this article are included in the article's Creative Commons licence, unless indicated otherwise in a credit line to the material. If material is not included in the article's Creative Commons licence and your intended use is not permitted by statutory regulation or exceeds the permitted use, you will need to obtain permission directly from the copyright holder. To view a copy of this licence, visit http://creativecommons.org/licen ses/by/4.0/.

\section{Appendix}

See Tables 7 and 8.

Footnote 22 (continued)

adopted by the authors (p. 275) is "the feeling that a weighted average of what is important for life is not bound to worsen". 
Table 7 Panel tobit Estimates including the results of the first experimental round

\begin{tabular}{lccc}
\hline Variables & $(1)$ & $(2)$ & $(3)$ \\
& Contribution & Contribution & Contribution \\
\hline No information & -6.542 & -7.188 & -6.261 \\
Partial information (wage only) & $(7.706)$ & $(7.844)$ & $(7.692)$ \\
& -14.69 & -13.97 & -14.02 \\
Full information & $(7.691)^{*}$ & $(7.828)^{*}$ & $(7.696)^{*}$ \\
& 19.50 & 20.58 & 20.24 \\
Round & $(7.934)^{* *}$ & $(8.068)^{* *}$ & $(7.949)^{* *}$ \\
Time to choose & -6.143 & -5.640 & -6.122 \\
& $(0.786)^{* * *}$ & $(0.766)^{* * *}$ & $(0.786)^{* * *}$ \\
Male & 0.163 & & 0.160 \\
Constant & $(0.0570)^{* * *}$ & & $(0.0570)^{* * *}$ \\
Observations & & & -5.956 \\
Number of subjects & & $(6.052)^{* * *}$ & $(5.459)$ \\
\hline
\end{tabular}

Standard errors in parentheses

$* * * p<0.01, * * p<0.05, * p<0.1$

Table 8 Tobit regressions on the average contributions to the PGG

\begin{tabular}{|c|c|c|c|c|}
\hline Variables & (1) & (2) & (3) & (4) \\
\hline No information & $\begin{array}{r}-3.461 \\
(4.408)\end{array}$ & $\begin{array}{r}-4.179 \\
(4.489)\end{array}$ & $\begin{array}{r}-3.348 \\
(4.401)\end{array}$ & $\begin{array}{r}-3.079 \\
(3.333)\end{array}$ \\
\hline Partial information & $\begin{array}{r}-9.412 \\
(4.409)^{* *}\end{array}$ & $\begin{array}{r}-8.570 \\
(4.484)^{*}\end{array}$ & $\begin{array}{r}-9.097 \\
(4.419)^{* *}\end{array}$ & $\begin{array}{l}-7.211 \\
(3.345)^{* *}\end{array}$ \\
\hline Full information & $\begin{array}{l}10.83 \\
(4.529)^{* *}\end{array}$ & $\begin{array}{l}11.95 \\
(4.596)^{* * *}\end{array}$ & $\begin{array}{l}11.17 \\
(4.543)^{* *}\end{array}$ & $\begin{array}{c}7.500 \\
(3.441)^{* *}\end{array}$ \\
\hline Time to choose & $\begin{array}{l}0.191 \\
(0.077)^{* *}\end{array}$ & & $\begin{array}{l}0.184 \\
(0.078)^{* *}\end{array}$ & $\begin{array}{c}2.953 \\
(2.474)\end{array}$ \\
\hline Male & & & $\begin{array}{r}-2.445 \\
(3.206)\end{array}$ & $\begin{array}{r}-48.36 \\
(4.825)^{* * *}\end{array}$ \\
\hline Free rider & & & & $\begin{array}{c}0.245 \\
(0.0595)^{* * *}\end{array}$ \\
\hline Constant & $\begin{array}{l}17.04 \\
(7.668)^{* *}\end{array}$ & $\begin{array}{l}34.28 \\
(3.179)^{* * *}\end{array}$ & $\begin{array}{l}18.85 \\
(8.010)^{* *}\end{array}$ & $\begin{array}{l}18.08 \\
(6.070)^{* * *}\end{array}$ \\
\hline Observations & 160 & 160 & 160 & 160 \\
\hline LR Chi squared & 27.37 & 21.43 & 27.95 & 116.78 \\
\hline Pseudo R-squared & 0.0223 & 0.0175 & 0.0228 & 0.0952 \\
\hline
\end{tabular}

Standard errors in parentheses

$* * * p<0.01, * * p<0.05, * p<0.1$ 


\section{References}

Andreoni, J. (1988). Why free ride? Strategies and learning in public goods experiments. Journal of Public Economics, 37(3), 291-304.

Arnott, R., Greenwald, B., \& Stiglitz, J. (1994). Information and economic efficiency. Information Economics and Policy, 6(1), 77-82.

Boone, A., \& White, J. (2015). The effect of institutional ownership on firm transparency and information production. Journal of Financial Economics, 117(3), 508-553.

Botelho, Anabela, Harrison, Glenn W., Costa-Pinto, Lígia M., \& Ruström, Elisabet E. (2009). Testing static game theory with dynamic experiments: A case study of public goods. Games and Economic Behavior, 67(1), 253-265.

Bowles, S. (1998). Endogenous preferences: The cultural consequences of markets and other economic institutions. Journal of Economic Literature, 36(1), 75-111.

Bowles, S. (2011). Is liberal society a parasite on tradition? Philosophy \& Public Affairs, 39, 46-81.

Brandts, J., Riedl, A., \& van Winden, F. (2009). Competitive rivalry, social disposition and subjective well-being: an experiment. Journal of Public Economics, 93(11-12), 1158-1167.

Buckley, E., \& Croson, R. (2006). Income and wealth heterogeneity in the voluntary provision of linear public goods. Journal of Public Economics, 90(4-5), 935-955.

Cadsby, C., \& Maynes, E. (1998). Gender and free riding in a threshold public goods game: Experimental evidence. Journal of Economic Behavior \& Organization, 34(4), 603-620.

Camerer, C. (2003). Behavioral game theory. Princeton: Princeton University Press.

Canegallo, C., Ortona, G., Ottone, S., Ponzano, F., \& Scacciati, F. (2008). Competition versus cooperation: Some experimental evidence. Journal of Socio-economics, 37(1), 18-30.

Carpenter, J. (2005). Endogenous social preferences. Review of Radical Political Economics, 37, 63-84.

Carpenter, J., Liati, A., \& Vickery, B. (2006). They came to play, Middlebury College Economics Discussion Paper 06-02, Middlebury, Vermont, USA.

Chaudhuri, A. (2011). Sustaining cooperation in laboratory public goods experiments: A selective survey of the literature. Experimental Economics, 14(1), 47-83.

Cherry, T., Kroll, S., \& Shogren, J. (2005). The impact of endowment heterogeneity and origin on public good contributions: Evidence from the lab. Journal of Economic Behavior \& Organization, 57(3), 357-365.

Croson, R., Fatas, E., \& Neugebauer, T. (2005). Reciprocity, matching and conditional cooperation in two public goods games. Economics Letters, 87(1), 95-101.

Deffains, Bruno, Espinosa, Romain, \& Fluet, Claude. (2019). Laws and norms: Experimental evidence with liability rules. International Review of Law and Economics, 60, 105858.

Drouvelis, M., \& Grosskopf, B. (2016). The effects of induced emotions on pro-social behaviour. Journal of Public Economics, 134, 1-8.

Espín, A. M., Sánchez, A., \& Herrmann, B. (2017). Economic preferences 2.0: connecting competition, cooperation and inter-temporal preferences. CEDEX Discussion Paper 2017-04.

Falk, A., \& Fischbacher, U. (2006). A theory of reciprocity. Games and Economic Behavior, 54(2), 293-315.

Falk, A., \& Szech, N. (2013). Morals and markets. Science, 340, 707-711.

Fehr, E., Gächter, S., \& Kirchsteiger, G. (1997). Reciprocity as a contract enforcement device: Experimental evidence. Econometrica, 65(4), 833-860.

Fehr, E., \& Schmidt, K. (2001). Theories of fairness and reciprocity-evidence and economic applications. CEPR Discussion Paper n.2703: 1-56.

Fiala, L., \& Suetens, S. (2017). Transparency and cooperation in repeated dilemma games: A meta study. Experimental Economics, 20, 755-771.

Fischbacher, U., Gächter, S., \& Fehr, E. (2001). Are people conditionally cooperative? Evidence from a public goods experiment. Economics Letters, 71(3), 393-404.

Gächter, S., \& Fehr, E. (2002). Fairness in the Labour Market. In F. Bolle \& M. Lehmann-Waffenschmidt (Eds.), Surveys in experimental economics. Heidelberg: Springer.

Galbiati, R., \& Vertova, P. (2014). How laws affect behavior: obligations, incentives, and cooperative behavior. International Review of Law and Economics, 38, 48-57.

Garrone, G., \& Ortona, G. (2013). The correlates of subjective overall security. International Journal of Happiness and Development, 1(3), 274-293. 
Greiner, B., Ockenfels, A., \& Werner, P. (2011). Wage transparency and performance: A real effort experiment. Economics Letters, 111(3), 236-238.

Grossman, S., \& Hart, O. (1986). The costs and benefits of ownership: A theory of vertical and lateral integration. Journal of Political Economy, 94(4), 691-719.

Harsanyi, John C. (1982). Morality and the theory of rational behaviour. In Amartya Sen \& Bernard Williams (Eds.), Utilitarianism and beyond (pp. 39-62). Cambridge: Cambridge University Press.

Heinrich, J., Boyd, R., Bowles, S., Camerer, C., Fehr, E., Gintis, H., et al. (2001). In search of homo economicus: behavioral experiments in 15 small-scale societies. America Economic Review, 91(2), 73-78.

Heinrich, J., Ensminger, J., McElreath, R., Barr, A., Barrett, C., Bolyanatz, A., et al. (2010). Markets, religion, community size, and the evolution of fairness and punishment. Science, 327, 1480-1484.

Hermann, B., Thöni, C., \& Gächter, S. (2008). Antisocial punishment across societies. Science, 319, $1362-1436$.

Hillier, B. (1997). The economics of asymmetric information. London: Palgrave.

Hirsch, F. (1976). Social limits to growth. Cambridge: Harvard University Press.

Hirschman, A. (1982). Rival interpretations of market society: Civilizing, destructive, or feeble? Journal of Economic Literature, 20, 1463-1484.

Hoffman, E., McCabe, K., Shachat, J., \& Smith, V. (1994). Preferences, property rights, and anonymity in bargaining games. Games and Economic Behavior, 7, 346-380.

Holt, Charles, \& Sullivan, Sean P. (2017). Experimental economics and the law. In F. Parisi (Ed.), The Oxford handbook of law and economics. Oxford: Oxford University Press.

Işgın, E., \& Sopher, B. (2015). Information transparency, fairness and labor market efficiency. Journal of Behavioral and Experimental Economics, 58, 33-39.

Kim, J., Zhang, H., Li, L., \& Tian, G. (2014). Press freedom, externally-generated transparency, and stock price informativeness: International evidence. Journal of Banking \& Finance, 46, 299-310.

Layous, K., Katherine Nelson, S., Kurtz, J., \& Lyubomirsky, S. (2017). What triggers prosocial effort? A positive feedback loop between positive activities, kindness and well-being. The Journal of Positive Psychology, 12(4), 385-398.

Ledyard, J. (1995). Public goods: A survey of experimental research. In A. Roth \& J. Kagel (Eds.), A handbook of experimental economics (pp. 111-194). Princeton: Princeton University Press.

Li, P., \& He, H. (2013). Study of optimal contract under asymmetric information. In: Qin, E.., Shen, J., \& Dou, R. (Eds.) The 19th international conference on industrial engineering management. Heidelberg: Springer.

Lotito, G., Migheli, M., \& Ortona, G. (2013). Is cooperation instinctive? Evidence form the response times in a public goods game. Journal of Bioeconomics, 15(2), 123-133.

Lotito, G., Migheli, M., \& Ortona, G. (2015). An experimental inquiry into the nature of relational goods, and their impact on co-operation. Group Decision and Negotiation, 24, 699-722.

Marciano, A., \& Ramello, G. (2019). Law, economics and calabresi on the future of law and economics. European Journal of Law and Economics, 48, 1-12.

Migheli, M. (2015). Gender at work: Incentives and self-sorting. Journal of Behavioral and Experimental Economics, 55(1), 10-18.

Milgrom, P. R., \& Roberts, J. (1992). Economics, organization and management. Englewood Cliffs: Prentice-Hall.

Milinski, M., Semmann, D., \& Krambeck, H.-J. (2002). Reputation helps solve the 'Tragedy of the Commons'. Nature, 415, 424-426.

Moffatt, P. (2016). Experimetrics. New York: Palgrave MacMillan.

Niederle, M., \& Vesterlund, L. (2007). Do women shy away from competition? Do Men Compete too much? The Quarterly Journal of Economics, 122(3), 1067-1101.

Piovesan, M., \& Wengström, E. (2009). Fast or fair? A study of response times. Economics Letters, 105(2), 193-196.

Rietz, T., Sheremeta, R., Shields, T., \& Smith, V. (2013). Transparency, efficiency and the distribution of economic welfare in pass-through investment trust games. Journal of Economic Behavior \& Organization, 94, 257-267.

Roth, A., Prasnikar, V., Okuno-Fujiwara, M., \& Zamir, S. (1991). Bargaining and market behavior in Jerusalem, Ljubljana, Pittsburgh, and Tokyo: An experimental study. American Economic Review, 81(5), 1068-1095.

Rousseau, D., \& Greller, M. (1994). Human resource practices: Administrative contract makers. Human Resource Management, 33, 384-401. 
Rubinstein, A. (2007). Instinctive and cognitive reasoning: A study of response times. The Economic Journal, 117(523), 1243-1259.

Rubinstein, A. (2013). Response time and decision making: An experimental study. Judgment and Decision Making, 8(5), 540-551.

Schotter, A., Weiss, A., \& Zapater, I. (1996). Fairness and survival in ultimatum and dictatorship games. Journal of Economic Behavior \& Organization, 31, 37-56.

Spier, K. (1992). Incomplete contracts and signalling. The Rand Journal of Economics, 23(3), 432-443.

Sugden, R. (2018). The community of advantage. Oxford: Oxford University Press.

Vishwanath, T., \& Kaufmann, D. (2001). Toward transparency: New approaches and their application to financial markets. The World Bank Research Observer, 16(1), 41-57.

Publisher's Note Springer Nature remains neutral with regard to jurisdictional claims in published maps and institutional affiliations. 